\title{
Letter-naming as a function of intensity, degradation, S-R compatibility, and practice
}

\author{
B. L. EVERETT, LARRY HOCHHAUS, and JOE RAY BROWN \\ Oklahoma State University, Stillwater, Oklahoma
}

\begin{abstract}
The purpose of the present experiment was to evaluate the effects of visual stimulus intensity, visual degradation, stimulus-response compatibility, and practice on vocalization latency in a letter-naming task. By means of a factorial design, 12 college students each received all treatment combinations across each of 3 days. Analysis of variance showed that each of the four manipulations had a significant effect on mean letter-naming time, but no two-factor or higher order interaction was significant. Error rate was affected only by degradation. Using the logic of the additive factor method, the data are consistent with Sanders' (1983) four-stage model of visual character identification in which recognition intensity, degradation, compatibility, and practice affect serial stages corresponding to preprocessing, feature extraction, response choice, and motor adjustment operations. When the less restrictive assumptions of McClelland's (1979) cascade model are applied, the data permit the inference of multiple processes and support the conclusion that at least three hypothetical components represent information processing in the task.
\end{abstract}

The experiment to be described was conducted to evaluate the manner in which intensity, degradation, stimulusresponse compatibility, and practice affect vocalization latency in a letter-naming task. Prior research that used pairwise contrasts provides evidence that intensity, degradation, and compatibility show additive contributions to mean response latency, but to date all have not been examined within a single experiment. We felt it was important to incorporate each of these variables into the present experiment. Such research could confirm the earlier studies which had shown pairwise additivity in subsets of the intensity, degradation, and compatibility manipulations. Also, the higher-order interaction component of the three variables could be determined. In addition, by including practice in the design, it might be possible to determine the manner in which practice reduces vocalization latency in the letter-naming task.

We adopted the perspective of the discrete stages model of the decision process with the practical understanding that its strict assumptions are frequently difficult to satisfy in even the most careful laboratory tests. Discrete stage models (Donders, 1869/1969; Sternberg, 1967) make three assumptions: that stages exist, that total decision time is the sum of component stage durations, and that the information output of a stage is independent of its duration. (See Pachella, 1974; Salthouse, 1981; Sanders, 1980; and Sternberg, 1969, for reviews.) The logic of the additive

\footnotetext{
We gratefully acknowledge the suggestions and comments made on earlier drafts of this article by Diana M. Byrd, C. W. Eriksen, Rebecca Logsdon, Robert J. Weber, Harold L. Williams, and two anonymous reviewers. We also wish to thank John Goetz and Nancy Martin for their help in data collection. The present research was supported, in part, by a grant from the State of Oklahoma to the second author.

The author's mailing address is: Psychology Department, Oklahoma State University, Stillwater, OK 74078.
}

factor method (Sternberg, 1969) dictates that if multiple independent variables show additive contributions to mean response latency, the variables probably affect independent stages of processing. Conversely, if variables are interactive in decision-time effects, the variables probably affect a common stage of processing.

A variety of experiments have reported the effects of different pairs of intensity, degradation, and compatibility variables on recognition processes. Most are consistent with an independent stage conceptualization of visual character recognition. Stimulus intensity and visual degradation have been shown to produce additive contributions to total decision time (Frowein, Gaillard, \& Varey, 1982; Sanders, 1980). Similarly, stimulus degradation and stimulus-response compatibility are also additive (Frowein, 1981; Sanders, 1970, 1977; Shwartz, Pomerantz, \& Egeth, 1977, Experiment 2; Sternberg, 1969; Tharp, Rundell, Lester, \& Williams, 1974). Additive effects have also been produced by stimulus intensity and stimulusresponse compatibility (Sanders, 1977; Shwartz et al., 1977, Experiment 1).

Using a somewhat atypical definition of stimulusresponse compatibility, Stanovich and Pachella (1977) found an interaction effect of visual stimulus intensity and "S-R compatibility." They defined degree of compatibility as the difference between spoken versus typed responses. Sanders (1980) suggested that the interaction of intensity and compatibility in the data of Stanovich and Pachella could be explained by methodological problems. A near-threshold value in their low-intensity condition may have produced a distorted signal. Additionally, Stanovich and Pachella's subjects were not highly practiced. This was especially true in the "incompatible" task, in which the fingers on left and right hands were sequentially assigned the numbers 1-8. Questions about the in- 
terpretation of Stanovich and Pachella's data suggest that their results are not detrimental to the view that intensity, degradation, and compatibility affect independent stages.

The results of the experiments reviewed above are neatly summarized by a recent stage model proposed by Sanders (1983). According to this view, four stages (preprocessing, feature extraction, response choice, and motor adjustment) represent important independent components of the character-recognition process. Sanders suggests that each hypothetical stage is identifiable by a specific marker variable. The first three stages, respectively, correspond to experimental manipulations of intensity, degradation, and compatibility. A fourth variable, time uncertainty, not covered by the present review, is suggested by Sanders as a marker for the final, motoradjustment stage.

Based on prior experiments and on Sander's theoretical model, we hypothesized that, when combined in a single multifactor experiment, intensity, degradation, and stimulus-response compatibility were mutually independent in their contributions to letter-naming time. We were less certain of what to expect concerning the practice variable. Although letter-naming is a highly overlearned activity, pilot data had indicated that improvement with practice was likely.

\section{METHOD}

\section{Subjects}

The subjects were 12 college graduate and undergraduate students, 20 to 35 years of age. Undergraduates were given a small amount of extra credit in their psychology class for participation. All subjects were tested individually on each of 3 days.

\section{Apparatus}

An APPLE II microcomputer, modified according to Reed (1979), and a Sanyo video monitor (Model VM 4509) were used to present $2.7 \times 2 \mathrm{~cm}$ white block letters on the $15 \times 19.5 \mathrm{~cm}$ video screen. Twenty-four letters ( $\mathrm{Y}$ and $\mathrm{Z}$ excluded) were presented. Intensity (contrast) was controlled by means of a device described by Hochhaus, Carver, and Brown (1983).

The degradation variable was provided by superimposing a 2.5 $\times 2 \mathrm{~cm}$ black and white checkerboard mask over the printed letter. Squares within the mask were $5 \times 4 \mathrm{~mm}$. On low intensity, degraded-target trials, the contrast of both the mask and target letter was reduced. Luminance values in the standard condition were $0.03 \mathrm{~cd} / \mathrm{m}^{2}$ (background) and $141.5 \mathrm{~cd} / \mathrm{m}^{2}$ (white figure). Corresponding values in the low intensity condition were 0.03 and 3.77 $\mathrm{cd} / \mathrm{m}^{2}$, respectively. A sound-activated relay and microphone was used to detect onset of the spoken responses. Vocalization latency was defined as the period from the onset of the visual stimulus letter to the onset of the vocal response and was recorded by a software clock (Price, 1979).

\section{Procedure}

Subjects were asked to perform the task as quickly as possible while minimizing errors. They were told that different intensities would be shown and that a mask would sometimes be present. In the compatible condition, subjects named, then (in order to record accuracy) typed, the letter presented. In the incompatible condition, subjects named, then typed, the next letter of the alphabet (e.g., shown A, say, type B, etc.). Prior to each letter presentation, the subjects were informed on the screen whether the next trial was to be performed by means of "standard responses" (compatible) or by means of "coded responses" (incompatible). Through randomization, however, the subjects were unaware of which intensity or degradation condition would appear on a given trial.

Trials were subject-paced and were administered in blocks of 48 letters. Each block (about $10 \mathrm{~min}$ ) consisted of two presentations of each of the 24 letters in a random order. Each combination of treatment conditions was presented equally often in each block, and across blocks the assignment of letters to treatment conditions was balanced. Day 1 consisted of one practice block; Days 2 and 3 each consisted of one practice block followed by four test blocks. Feedback based on accuracy was given after each block of trials by the computer. The subjects were told to (1) "speed up" (errors < 1\%), (2) "stay the same speed" (errors $=2 \%$ ), or (3) "slow down" (errors $>2 \%$ ).

\section{RESULTS}

Data from the practice day and the practice blocks of test days were excluded from analysis. Values of mean correct naming time were evaluated by a $2 \times 2 \times 2 \times 2$ repeated measures variance analysis. Factors and their levels were days (Day 2 vs. Day 3), intensity (low vs. high), degradation (intact vs. degraded), and compatibility (compatible vs. incompatible). All main-effect hypotheses and all interaction terms were evaluated. The proportions of total naming-time treatment variance were also estimated for each main and interaction effect. Due to the nature of the present experimental design, however, estimates of variance components including error terms could not be made (Ostle, 1963; Vaughn \& Corballis, 1969).

Figure 1 shows the mean correct vocalization latency for each combination of treatment conditions. Error rates are shown in parentheses. Treatment variance components and the results of the significance tests of mean correct vocalization time and percent error are summarized in Table 1 . In the vocalization-time analysis, main effect differences (and proportion of treatment variance explained) for days, intensity, degradation, and compatibility were $100 \mathrm{msec}(4 \%), 40 \mathrm{msec}(1 \%), 110 \mathrm{msec}(6 \%)$, and $425 \mathrm{msec}(88 \%)$, respectively. Each difference is statistically reliable. No interaction term reached statistical significance in the vocalization-time analysis, but the days $x$ intensity interaction appreached reliability. The combination of all two-factor and higher-order interactions accounted for less than $1 \%$ of the total vocalization-time treatment variability.

Analysis of percent errors revealed highly accurate task performance $(M=.8 \%, S D=.4 \%)$. As shown in Table 1 , only the degradation factor significantly affected error rate. There were more errors when stimuli were degraded (1\%) than when they were intact (.6\%). Effects on errors produced by the compatibility and the degradation $\times$ compatibility interaction factors approached reliability. Error rates for the various combinations of treatment conditions are shown in parentheses in Figure 1.

\section{DISCUSSION}

These data were analyzed from the perspective of the additive factor method, which assumes a stage model 

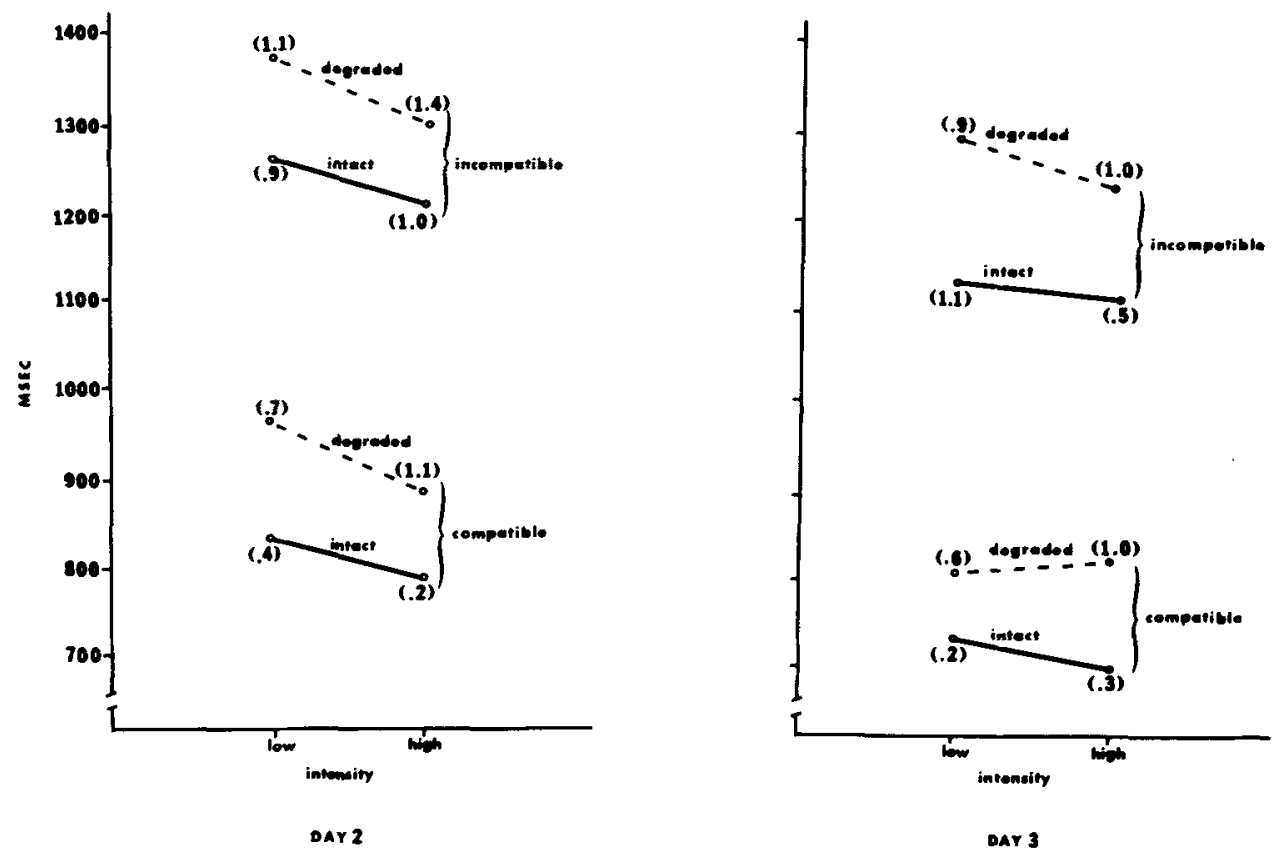

Figure 1. Mean reaction time as a function of visual stimulus intensity, visual degradation, stimulus-response compatibility instructions, and practice. Error rates are shown in parentheses.

characterization of the decision process. The mutual independence of the four variables, intensity, degradation, compatibility, and practice, implies the operation of at least four stages in the present letter-naming task. As such, the results are consistent with Sander's (1983) four-stage model, with practice impacting the final, motoradjustment stage of processing. According to this view, Stages 1-4 (preprocessing, feature extraction, response choice, and motor adjustment) are influenced by stimulus intensity, masking degradation, stimulus-response compatibility, and practice, respectively. If these inferences are correct, one would predict an interaction of practice and time uncertainty based on the Sanders model and the present results.

The significant effect of degradation on errors suggests caution in evaluating the additive naming-time effects of degradation with other variables. As Pachella has frequently noted, small changes in accuracy, especially when accuracy is high, can cause substantial changes in decision time (e.g., Pachella, 1974). Influences produced by shifts on the curve relating speed and accuracy could, therefore, serve to mask interaction effects involving degradation and other variables.

Garner (1974) has noted that experimental manipulations may be either state limiting, that is, may affect the amount and quality of information available for decision making, or may be process limiting, indicating that their effects operate on the discriminability of stimulus patterns. If degradation reduced discriminability in the visual display, as suggested by its significant effect on errors, it may limit the output of a component process rather than its duration. If stage model assumptions are not met as suggested by the degradation error differences, the conclusion that the data reflect four stages must be qualified.
Many authors challenge the presuppositions of stage models (e.g., Eriksen \& Schultz, 1979; Grice, Nullmeyer, \& Spiker, 1982; McClelland, 1979; Schweikert, 1983; Taylor, 1976; Turvey, 1973). These writers show that when one or more of the stage-model assumptions are relaxed, additive and interactive decision-time effects become multiinterpretable. McClelland's (1979) highly formalized continuous processing model provides a specific comparison of inferences permitted by stage-model assumptions with his cascade-model alternative. McClelland's model permits overlap in subprocesses and also asserts that manipulations may affect rate of processing or may affect the output of a subprocess (that is, change the speed-accuracy tradeoff curve asymptote). By this view,

Table 1

F Tests of Mean Reaction Time and Percent Error as a Function of Days of Practice, Intensity, Degradation, and Stimulus-Response Compatibility

\begin{tabular}{lcc} 
& \multicolumn{2}{c}{ F Values } \\
\cline { 2 - 3 } Source & Reaction Time & Percent Error \\
\hline Practice (P) & $8.31^{*}$ & .28 \\
Intensity (I) & $5.61^{*}$ & .50 \\
Degradation (D) & $18.27^{* *}$ & $5.94^{*}$ \\
Compatibiity (C) & $28.51^{\dagger}$ & 4.20 \\
$\mathrm{P} \times \mathrm{I}$ & 3.58 & .44 \\
$\mathrm{P} \times \mathrm{D}$ & .45 & .19 \\
$\mathrm{P} \times \mathrm{C}$ & .15 & .18 \\
$\mathrm{I} \times \mathrm{D}$ & .30 & 2.53 \\
$\mathrm{I} \times \mathrm{C}$ & .44 & .57 \\
$\mathrm{D} \times \mathrm{C}$ & .29 & 4.42 \\
$\mathrm{P} \times \mathrm{I} \times \mathrm{D}$ & .24 & .02 \\
$\mathrm{P} \times \mathrm{I} \times \mathrm{C}$ & .33 & 1.11 \\
$\mathrm{I} \times \mathrm{D} \times \mathrm{C}$ & 1.28 & .02 \\
$\mathrm{P} \times \mathrm{I} \times \mathrm{D} \times \mathrm{C}$ & .69 & 2.67 \\
\hline
\end{tabular}

${ }^{*} p<.05 . \quad{ }^{* *} p<.01 . \quad+p<.001$. 
additive effects may occur when one variable affects the rate of a subprocess while another affects the output of that subprocess. The cascade model further specifies, however, that if each of two variables affects the asymptote (as might be the case with two-process limiting variables), the variables will tend to interact. Given the cascade-model assumptions, therefore, the independence of the four variables in the present experiment suggests that, at most, only one of the factors is affecting subprocess outputs. Consequently, according to logic based on the cascade-model assumptions, the data of the present experiment imply that the letter-naming task involves at least three component processes.

In summary, the data show that intensity, degradation, stimulus-response compatibility, and practice are additive in their effects on visual letter-naming. Because degradation affected errors also, caution should be exercised in inferences concerning the independence of its vocalization time effects from the remaining variables. Given stage-model assumptions, the data support the inference that four or more stages of operations characterize the letter-naming process. Less restrictive assumptions associated with the continuous-processing, cascade model of McClelland (1979) still permit the inference of multiple processes based on the fact that, according to McClelland, factors that mutually affect the asymptotic output of a single stage will tend to interact. The perspective and logic of the cascade model suggest that at least three hypothetical components of information processing represent performance in the present letter-naming task.

\section{REFERENCES}

Donders, F. C. (1869). Over de snelheid van psychische processen. Onderzoekingen in het Physiologish Laboratorium der Utrechtsche Hoogeshool, 1868-1869, Tweede Reeks, II, 92-120. In W. G. Koster (Ed. and Trans.), Attention and performance, II. Amsterdam: North Holland, 1969. (Reprinted from Acta Psychologica, 1969, 30, 412-431.)

ERIKSEN, C. W., \& SchultZ, D. W. (1979). Information processing in visual search: A continuous flow conception and experimental results, Perception \& Psychophysics, 25, 249-263.

FrowEIN, H. W. (1981). Selective drug effects on human information processing. Soesterberg, The Netherlands: Institute for Perception TNO.

Frowein, H. W., Gaillard, A. W., VArey, C. A. (1982). EP components, visual processing stages and the effects of a barbiturate. $B i$ ological Psychology, 13, 239-249.

GARNER, W. R. (1974). The processing of information and structure. Potomac, MD: Erlbaum.

GRICE, G. R., Nullmeyer, R., S SiKer, V. A. (1982). Human reaction time: Toward a general theory. Joumal of Experimental Psychology: General, 111, 135-153.
Hochhaus, L., Carver, S., \& Brown, J. R. (1983). Control of CRT intensity via Apple II software. Behavior Research Methods \& Instrumentation, 15, 594-597.

MCClellaNd, J. L. (1979). On the time relations of mental processes: An examination of systems of processes in cascade. Psychological Review, 86, 287-330.

OSTLE, B. (1963). Statistics in research (2nd ed.). Ames: lowa State University Press.

Pachella, R. G. (1974). The interpretation of reaction time in information processing. In $\mathrm{B}$. Kantowitz (Ed.), Tutorials in performance and cognition (pp. 41-82). Hillsdale, NJ: Erlbaum.

PrICE, J. M. (1979). Software timing for 6500 series microcomputers. Behavior Research Methods \& Instrumentation, 11, 568-571.

ReED, A. V. (1979). Microcomputer display timing: Problems and solutions. Behavior Research Methods \& Instrumentation, 11, 572-576.

Salthouse, T. A. (1981). Converging evidence for informationprocessing stages: A comparative-influence stage-analysis method. Acta Psychologica, 47, 39-61.

SANDERS, A. F. (1970). Some variables affecting the relation between relative signal frequency and CRT. Acta Psychologica, 33, 45-55.

SANDERS, A. F. (1977). Structural and functional aspects of the reaction process. In S. Dornic (Ed.), Attention and performance, VIII (pp. 3-25). Hillsdale, NJ: Erlbaum.

SANDERS, A. F. (1980). Stage analysis of reaction processes. In G. E. Stelmach \& J. Requin (Eds.), Tutorials in motor behavior (pp. 331354). Amsterdam: North-Holland.

SANDERS, A. F. (1983). Towards a model of stress and human performance. Acta Psychologica, 53, 61-97.

SCHWEIKERT, R. (1983). Latent network theory: Scheduling of processes in sentence verification and the Stroop effect. Journal of Experimental Psychology: Learning, Memory, and Cognition, 9, 353-383.

Shwartz, S. P., Pomerantz, J. R., \& Egeth, H. E. (1977). State and process limitations in information processing: An additive factors analysis. Journal of Experimental Psychology: Human Perception and Performance, 3, 402-410.

Stanovich, K. E., Pachella, R. G. (1977). Encoding, stimulusresponse compatibility, and stages of processing. Joumal of Experimental Psychology: Human Perception and Performance, 3, 411-421.

STERNBERG, S. (1967). Two operations in character recognition: Some evidence from reaction time measurements. Perception \& Psychophysics, 2, 45-53.

STERnBerG, S. (1969). On the discovery of processing stages: Some extensions of Donder's method. Acta Psychologica, 30, 276-315.

TAYLOR, D. A. (1976). Stage analysis of reaction time. Psychological Bulletin, 83, 161-191.

TharP, V. K., Rundell, O. H., Lester, B. K., \&illiams, H. L. (1974). Alcohol and information processing. Psychopharmacologia, 40, 33-52.

TURVEY, M. (1973). On peripheral and central processes in vision: Inferences from an information-processing analysis of masking with patterned stimuli. Psychological Review, 80, 1-52.

Vaughn, G. M., \& Corballis, M. C. (1969). Beyond tests of significance: Estimating strength of effects in selected ANOVA designs. Psychological Bulletin, 72, 204-213.

(Manuscript received March 1, 1985; revision accepted for publication April 4, 1985.) 